The Texas Medical Center Library

DigitalCommons@TMC

The University of Texas MD Anderson Cancer Center UTHealth Graduate School of

Biomedical Sciences Dissertations and Theses

(Open Access)
The University of Texas MD Anderson Cancer

Center UTHealth Graduate School of

Biomedical Sciences

\title{
$5-2017$
}

\section{The Utilization of Prenatal Microarray: A Survey of Current Genetic Counseling Practices and Barriers}

Leslie N. Durham

Leslie Durham

Follow this and additional works at: https://digitalcommons.library.tmc.edu/utgsbs_dissertations

Part of the Genetics Commons, Medical Genetics Commons, and the Obstetrics and Gynecology

Commons

\section{Recommended Citation}

Durham, Leslie N. and Durham, Leslie, "The Utilization of Prenatal Microarray: A Survey of Current Genetic Counseling Practices and Barriers" (2017). The University of Texas MD Anderson Cancer Center UTHealth Graduate School of Biomedical Sciences Dissertations and Theses (Open Access). 761.

https://digitalcommons.library.tmc.edu/utgsbs_dissertations/761

This Thesis (MS) is brought to you for free and open access by the The University of Texas MD Anderson Cancer Center UTHealth Graduate School of Biomedical

Sciences at DigitalCommons@TMC. It has been accepted for inclusion in The University of Texas MD Anderson Cancer Center UTHealth Graduate School of Biomedical Sciences Dissertations and Theses (Open Access) by an authorized administrator of DigitalCommons@TMC. For more information, please contact digitalcommons@library.tmc.edu.

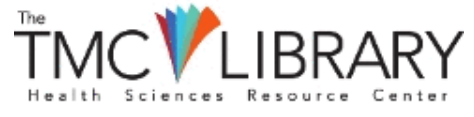


THE UTILIZATION OF PRENATAL MICROARRAY: A SURVEY OF CURRENT GENETIC COUNSELING PRACTICES AND BARRIERS

\section{By}

Leslie Durham, B.S., B.A.

\section{APPROVED:}

Nevena Krstic, M.S., C.G.C.

Advisory Professor

Sarah Noblin, M.S., C.G.C

Ramesha Papanna, M.D.

David Rodriguez-Buritica, M.D.

Blair Stevens, M.S., C.G.C.

APPROVED:

Dean, The University of Texas MD Anderson Cancer Center UTHealth Graduate School of Biomedical Sciences 


\title{
THE UTILIZATION OF PRENATAL MICROARRAY: A SURVEY OF CURRENT GENETIC COUNSELING PRACTICES AND BARRIERS
}

\author{
A \\ THESIS \\ Presented to the Faculty of \\ The University of Texas \\ MD Anderson Cancer Center UTHealth \\ Graduate School of Biomedical Sciences \\ in Partial Fulfillment of the Requirements \\ for the Degree of \\ MASTER OF SCIENCE \\ By \\ Leslie Durham, B.S., B.A. \\ Houston, Texas \\ May 2017
}




\section{Acknowledgements}

This project was a collaboration of many talented people. I have had wonderfully

insightful committee chair, Nevena Krstic, who has continually pushed me to become not only a better genetic counselor, but a better research and writer as well. Thank you for all of your ideas, support, and astute edits throughout this process. Additionally, I would like to thank my committee members: Dr. Ramesha Papanna,

Blair Stevens, Sarah Noblin, and Dr. David Rodriguez for their support and contributions the last year and a half.

Thank you to the University of Texas Genetic Counseling Program:

Claire Singletary, Jennifer Czerwinski, Telisha Green and numerous other supervisors who have encouraged and supported me through this graduate program.

Thank you to my wonderful family and classmates for all their support the last two years. I would especially like to thank my fiancé for not only being willing to drop everything and move with me to begin graduate school, but also for his endless encouragement and love during this journey.

I have made 7 new best friends during my time here in Houston, we continually count ourselves lucky that we all happened to choose this program and get put together because without them I don't think I would have done nearly as well in graduate school. Meagan Kaulfus, Katy Reese, Chelsea Wagner, Maggie Clifford, Jordan Berg, Amanda Gerard, and Ellen Zirkelbach I am so lucky to have gotten to know you and my life is 1,000 times better because of it. 


\title{
THE UTILIZATION OF PRENATAL MICROARRAY: A SURVEY OF CURRENT GENETIC COUNSELING PRACTICES AND BARRIERS
}

\author{
Leslie Durham, B.S., B.A. \\ Advisory Professor: Nevena Krstic, M.S., C.G.C.
}

\section{Abstract:}

Chromosomal microarray (CMA) assesses chromosome copy number variants (CNVs) missed by standard karyotyping. The American College of Obstetricians and Gynecologists (ACOG) recommends CMA for all patients with fetuses with an ultrasound anomaly and suggests that it be made available to all women undergoing invasive testing. In order to assess prenatal genetic counselors' (GCs) practices regarding the utilization of CMA we conducted a survey of their current practices, attitudes, and perceived barriers. Of the 192 respondents, 183 (95\%) have incorporated CMA into clinical practice with the majority (64\%) believing that the benefits of CMA outweigh the harms. However, only half $(52 \%)$ of the respondents agreed that CMA should be offered to all women regardless of indication. The respondents who reported feeling that they were experts/comfortable in their knowledge of CMA (85\%) and were familiar with current clinical guidelines (86\%) were significantly more likely to offer CMA to all patients undergoing invasive testing, patients with fetuses with anomalies, and those referred for advanced maternal age. Genetic counselors report not offering CMA to patients due to patient specific concerns (51\%), such as anxiety or health literacy, financial concerns (39\%), 
difficulty of interpreting results (39\%), lack of data (36\%), and time constraints (22\%). Patient specific concerns were the largest reported barrier when GCs chose not to offer CMA to patients which, is different than the studies which predate the ACOG guidelines that cited financial and ethical concerns as barriers. Our study demonstrates that GCs follow established guidelines for use of CMA when specific indications are involved but further guidelines are needed regarding use of CMA for other common prenatal indications. Based on this, other professional societies such as National Society of Genetic Counselors should consider publishing guidelines on prenatal CMA that are specialized to the GCs sphere of practice. 


\section{Table of Contents:}

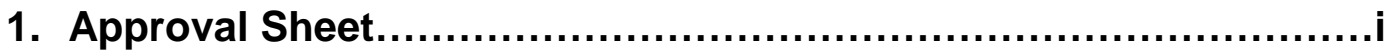

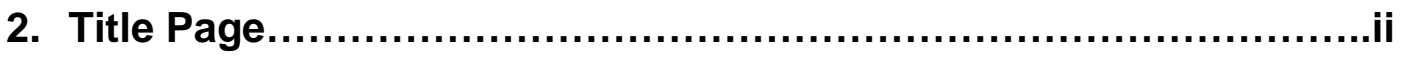

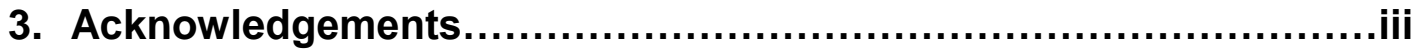

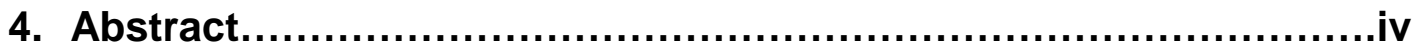

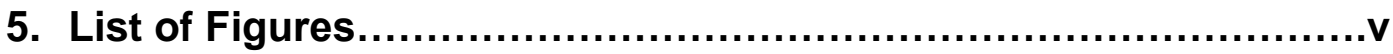

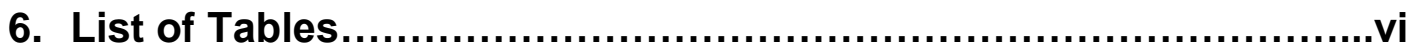

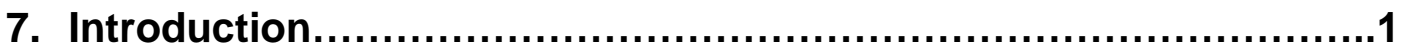

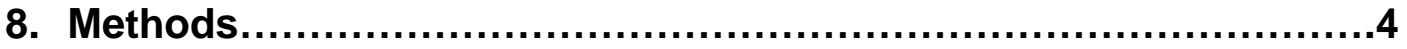

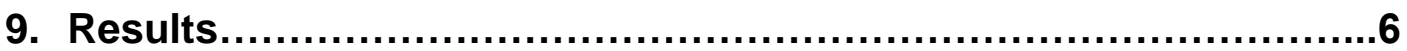

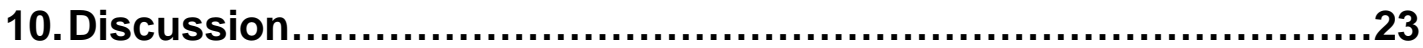

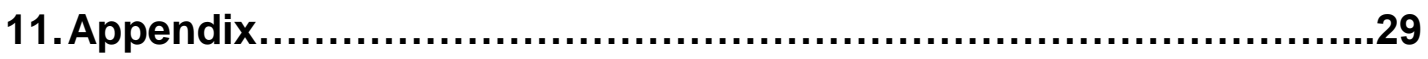

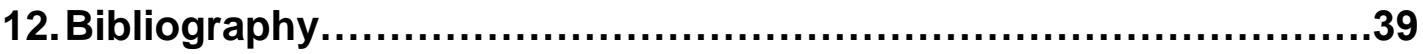

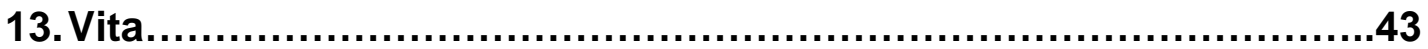




\section{List of Figures:}

1. Figure 1: Percentage of Patients Seen with the Following Insurance

Coverage

2. Figure 2: Frequency Prenatal CMA is Offered Given the Following

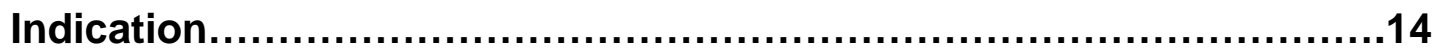

3. Figure 3: Factors that Play a Role when Prenatal CMA is not Offered to

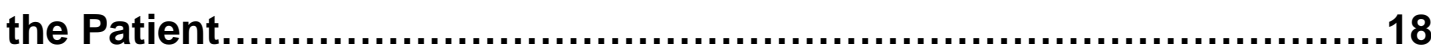

4. Figure 4: Frequency of Pre-Test Counseling Discussion Points for

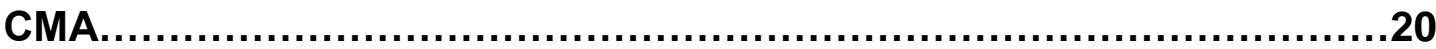

5. Figure 5: Resources Used to Stay Current on Information About

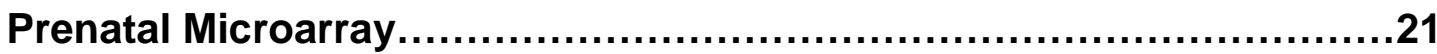




\section{List of Tables:}

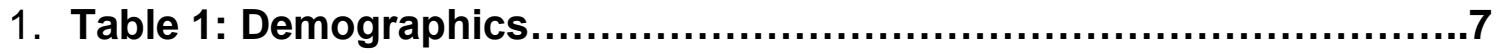

2. Table 2: Knowledge and Beliefs.............................................12 


\section{Introduction}

Chromosomal microarray analysis (CMA) is a genetic test that can identify chromosomal aneuploidy as well as chromosomal microduplications and microdeletions, referred to as copy number variants (CNVs). CNVs are often too small to be detected by a conventional karyotype, but are implicated as a cause of multiple genetic disorders that may manifest as congenital anomalies or a fetal demise during pregnancy ${ }^{1}$.

CMA has been used in pediatric and adult genetic clinics for over a decade, and the American Academy of Pediatrics recommends CMA as a first-tier test for individuals with autism spectrum disorder, developmental delay, unexplained intellectual disability, and multiple congenital anomalies ${ }^{2}$.

In 2012 a multi-center prospective trial conducted by the National Institute of Child Health and Human Development (NICHD) showed that, in the presence of a normal karyotype, approximately $6 \%$ of pregnancies with fetal anomalies detected on ultrasound, and $1.7 \%$ of pregnancies with routine indications, such as advanced maternal age, had clinically significant CNVs detected on prenatal CMA ${ }^{3}$. Subsequent studies showed higher detection rates of CNVs, $6.5 \%$ in the presence of an abnormal fetal ultrasound, and $8.2 \%$ in the presence of fetal demise ${ }^{1}$.

Based on this, the American College of Obstetricians and Gynecologists (ACOG), in conjunction with the Society for Maternal and Fetal Medicine (SMFM), published a joint statement in 2013 recommending CMA as the first-line test when a prenatal ultrasound shows one or more major fetal abnormalities ${ }^{4}$. Guidelines also 
recommend CMA as the preferred genetic test to help identify the cause of fetal demise and stillbirth, and that CMA should be made available to any patient undergoing diagnostic testing ${ }^{4}$. This was later reinforced by the updated 2016 ACOG and SMFM practice bulletin which further stated that CMA should be a primary test, replacing karyotype, for patients with fetal structural abnormalities ${ }^{5}$. However, more prospective studies are needed to demonstrate the diagnostic utility and benefit, as well as cost effectiveness of prenatal microarray in all pregnant women.

One major complication with the technology of prenatal microarray is the detection of CNVs of unknown significance, also referred to as variants of uncertain significance (VUS), and the difficulty of interpreting VUS results ${ }^{6}$. The overall VUS rate in prenatal CMA is reported to be $1.5 \%-1.6 \%{ }^{7,8}$. Information regarding CNVs that are detected prenatally or in healthy individuals is very limited. In the hopes to improve these gaps, several databases, such as ClinVar and DECIPHER, have been established to help collect and distribute such information ${ }^{9,10}$. Parental or family studies can aid in reclassification of variants given that CNVs inherited from an unaffected parent tend to be benign, however, parental blood samples are not always available for analysis, and incomplete penetrance cannot be excluded ${ }^{11}$. For patients undergoing prenatal microarray testing, the uncertainty about the predicted clinical phenotype and lack of precise risk estimate associated with VUS, particularly in the absence of congenital abnormalities, may increase parental and family anxiety and distress, as well as impact decision making regarding the pregnancy ${ }^{15}$. 
Additionally, studies on cost effectiveness of CMA in prenatal diagnosis are limited. Test coverage by insurance companies also varies. While many insurance providers deem CMA to be "medically appropriate and/or necessary" in cases of fetal structural abnormalities, many insurance companies still consider CMA to be "investigational" or "experimental" and are not routinely covering the testing especially in the absence of ultrasound abnormalities or other high risk factors ${ }^{12-14}$.

Appropriate pretest and posttest genetic counseling, with a thorough discussion of the benefits and limitations, is warranted for patients undergoing prenatal microarray. ACOG recommends that certain points should be shared with the patients prior to undergoing CMA and these include, but are not limited to, that results may or may not be informative in terms of identifying a known genetic condition, conditions detected by CMA may have high variability in clinical presentation, may identify consanguinity or non-paternity, and that results may identify adult-onset disease ${ }^{7}$.

While discussion and ordering of prenatal CMA can be done by various healthcare providers, genetic counselors are a subgroup of health professionals who are uniquely trained in counseling regarding the benefits, limitations, and risks associated with prenatal screening and testing options. Genetic counselors who counsel patients frequently order prenatal tests, interpret and disclose these results, and facilitate decision making and coordination of care following the results. Several studies have therefore looked at the experiences and attitudes of genetic counselors toward prenatal microarray. 
A 2012 survey of 160 prenatal genetic counselors practicing in North America showed that the majority $(73 \%)$ of respondents found prenatal microarray to be a useful tool, and $84 \%$ presented it to patients as a prenatal diagnostic option, but only $69 \%$ reported to have ordered a prenatal microarray at least once. Reported challenges included financial issues and ethical concerns, as well as the difficulty of interpreting uncertain results and explaining these complex results to patients ${ }^{16}$. Another study of 193 prenatal genetic counselors found that only $59 \%$ of counselors would be comfortable providing genetic counseling and $43 \%$ would be comfortable helping a patient make a decision about pregnancy termination in the presence of an uncertain microarray result ${ }^{17}$.

The above cited literature regarding the attitudes and practices of genetic counselors regarding microarray testing largely predate the ACOG guidelines released in December of $2013^{4}$ and all predate the recent 2016 practice bulletin ${ }^{5}$.

The current study aims to evaluate whether prenatal genetic counselors have incorporated prenatal microarray into their clinical practice within the framework of current guidelines, as well as their current practices regarding test ordering, pretest counseling, and informed consent. The study will clarify prenatal genetic counselor utilization as well as knowledge, beliefs, and perceived barriers toward implementation of prenatal microarray into clinical practice.

\section{Methods}

This study was approved by the Committee for the Protection of Human Subjects at the University of Texas McGovern Medical School at Houston (\#HSC- 
MS-16-0520). This was a survey based cross-sectional study of English-speaking, board certified or eligible genetic counselors who currently practice prenatal genetic counseling and discuss prenatal diagnostic testing options with patients. Participants for the study were recruited via an email to the members of the National Society of Genetic Counselors (NSGC). Participation was voluntary. Members who agreed to participate by providing informed consent were asked to complete an anonymous online survey. The incentive for the completion of survey was that the participants were given the option of providing their email address in a separate email apart from the survey if they wished to enter a drawing for a gift card.

The survey was created, distributed, and managed using Qualtrics online software (Qualtrics, Provo, Utah) approved for use by the University of Texas McGovern Medical School at Houston Institutional Review Board. The survey was created for the study but did not employ formal or validated measures. There were two arms to the survey, Arm A and Arm B, depending on if the participants did not or did incorporate CMA into their prenatal practice, respectively. The questions consisted of multiple choice, Likert scale, and free responses and were designed to assess demographic information, knowledge and beliefs, current practices of prenatal genetic counselors in regards to the use of CMA, and perceived barriers. The initial email was sent to the NSGC membership August 1, 2016 and a second reminder email was sent on September 12, 2016. Data collection was closed October $1^{\text {st }}$ and the survey link was deactivated. A full copy of the survey is available in the Appendix.

Data Analysis 
Descriptive statistics were presented as number (percentage) and mean \pm SD. Comparison of data generated from the survey questions was evaluated using Pearson Chi-square analysis and Fisher exact test. Findings were considered statistically significant if the $p$-value was $<0.05$ in this study. Data was analyzed using STATA software (v.14.1, College Station, TX).

\section{Results}

At the time our survey was distributed there were 3,189 counselors registered as members of NSGC. Of the 252 surveys that were started, a total of 192 participants completed the entire survey $(76 \%)$. The open rate was $27.6 \%$ for the first email and $26.3 \%$ for the second email. Per the 2016 professional survey, $43 \%$ are prenatal counselors that practice in a clinical setting.

\section{Demographics}

The majority of the participants reported having less than 10 years of total genetic counseling (70\%) and prenatal specific genetic counseling (73\%) experience, spending over half of their time counseling patients in a clinical setting (81\%), and seeing more than 10 patients per week (69\%). The greatest number reported working at an institution that had 5 or less genetic counselors (73\%), in a university medical center or academic institution (40\%), did not work for an institution associated with a laboratory that performs prenatal CMA (74\%), and did not work for a center that provides fetal intervention (71\%). A complete list of participant's demographics is summarized in Table 1. Most genetic counselors surveyed saw 
more patients with private insurance than Medicaid, state health insurance, and selfpay (Table 2).

Overall, the participants' reported demographic information was representative of the results gathered in the National Society of Genetic Counselors 2016 Professional Status Survey.

Table 1. Demographics

\begin{tabular}{|c|c|c|}
\hline Demographics & $\mathrm{N}=192$ & Percentage \\
\hline \multicolumn{3}{|c|}{ Years of genetic counseling experience } \\
\hline$<5$ & 92 & $48 \%$ \\
\hline $6-10$ & 42 & $22 \%$ \\
\hline $11-15$ & 21 & $11 \%$ \\
\hline $16-20$ & 18 & $9 \%$ \\
\hline$>20$ & 19 & $10 \%$ \\
\hline \multicolumn{3}{|c|}{ Years of prenatal genetic counseling experience } \\
\hline$<5$ & 105 & $55 \%$ \\
\hline
\end{tabular}




\begin{tabular}{|c|c|c|}
\hline $6-10$ & 35 & $18 \%$ \\
\hline $11-15$ & 21 & $11 \%$ \\
\hline $16-20$ & 17 & $9 \%$ \\
\hline$>20$ & 14 & $7 \%$ \\
\hline \multicolumn{3}{|c|}{ Time spent counseling in the clinical prenatal setting } \\
\hline $1-20 \%$ & 20 & $10 \%$ \\
\hline $21-40 \%$ & 17 & $9 \%$ \\
\hline $41-60 \%$ & 25 & $13 \%$ \\
\hline $61-80 \%$ & 34 & $18 \%$ \\
\hline $81-100 \%$ & 96 & $50 \%$ \\
\hline \multicolumn{3}{|c|}{ Prenatal patients seen per week } \\
\hline$<5$ & 24 & $13 \%$ \\
\hline $6-10$ & 35 & $18 \%$ \\
\hline $11-15$ & 64 & $33 \%$ \\
\hline $16-20$ & 48 & $25 \%$ \\
\hline$>20$ & 21 & $11 \%$ \\
\hline
\end{tabular}




\begin{tabular}{|c|c|c|}
\hline \multicolumn{3}{|l|}{ Work setting } \\
\hline University Medical Center/Academic Institution & 76 & $40 \%$ \\
\hline Private Hospital/Medical Facility & 45 & $23 \%$ \\
\hline Public Hospital/Medical Facility & 37 & $19 \%$ \\
\hline Government or Military Hospital/Medical Facility & 1 & $1 \%$ \\
\hline Private Practice/Office & 24 & $12 \%$ \\
\hline Commercial Diagnostic Laboratory & 5 & $3 \%$ \\
\hline Other & 4 & $2 \%$ \\
\hline \multicolumn{3}{|l|}{ Region of practice } \\
\hline $\begin{array}{c}\text { Region 1: } \\
\text { CT, MA, ME, NH, NY, RI, VT, CN, Maritime Provinces }\end{array}$ & 22 & $12 \%$ \\
\hline $\begin{array}{c}\text { Region 2: } \\
\text { DC, DE, MD, NJ, NY, PA, VA, WV, PR, VI, Quebec }\end{array}$ & 32 & $17 \%$ \\
\hline $\begin{array}{c}\text { Region 3: } \\
\text { AL, FL, GA, KY, LA, MS, NC, SC, TN }\end{array}$ & 22 & $11 \%$ \\
\hline $\begin{array}{c}\text { Region 4: } \\
\text { AR, IA, IL, IN, KS, MI, MN, MO, ND, } \\
\text { NE, OH, OK, SD, WI, Ontario }\end{array}$ & 48 & $25 \%$ \\
\hline $\begin{array}{c}\text { Region 5: } \\
\text { AZ, CO, MT, NM, TX, UT, WY, } \\
\text { Alberta, Manitoba, Saskatchewan }\end{array}$ & 29 & $15 \%$ \\
\hline
\end{tabular}




\begin{tabular}{|c|c|c|}
\hline $\begin{array}{r}\text { Region 6: } \\
\text { AK, CA, HI, NV, ID, OR, WA, }\end{array}$ & 39 & $20 \%$ \\
\hline \multicolumn{3}{|c|}{ Number of prenatal genetic counselors at institution } \\
\hline 0 & 40 & $21 \%$ \\
\hline $1-5$ & 101 & $53 \%$ \\
\hline $6-10$ & 28 & $15 \%$ \\
\hline $11-15$ & 16 & $8 \%$ \\
\hline$>15$ & 7 & $4 \%$ \\
\hline \multicolumn{3}{|c|}{ Work in a center that provides fetal intervention } \\
\hline Yes & 46 & $24 \%$ \\
\hline No & 137 & $71 \%$ \\
\hline Unsure & 9 & $5 \%$ \\
\hline \multicolumn{3}{|c|}{$\begin{array}{l}\text { Work for a hospital/laboratory/commercial entity that } \\
\text { performs prenatal CMA }\end{array}$} \\
\hline Yes & 47 & $24 \%$ \\
\hline No & 141 & $74 \%$ \\
\hline Unsure & 4 & $2 \%$ \\
\hline
\end{tabular}


Figure 1.

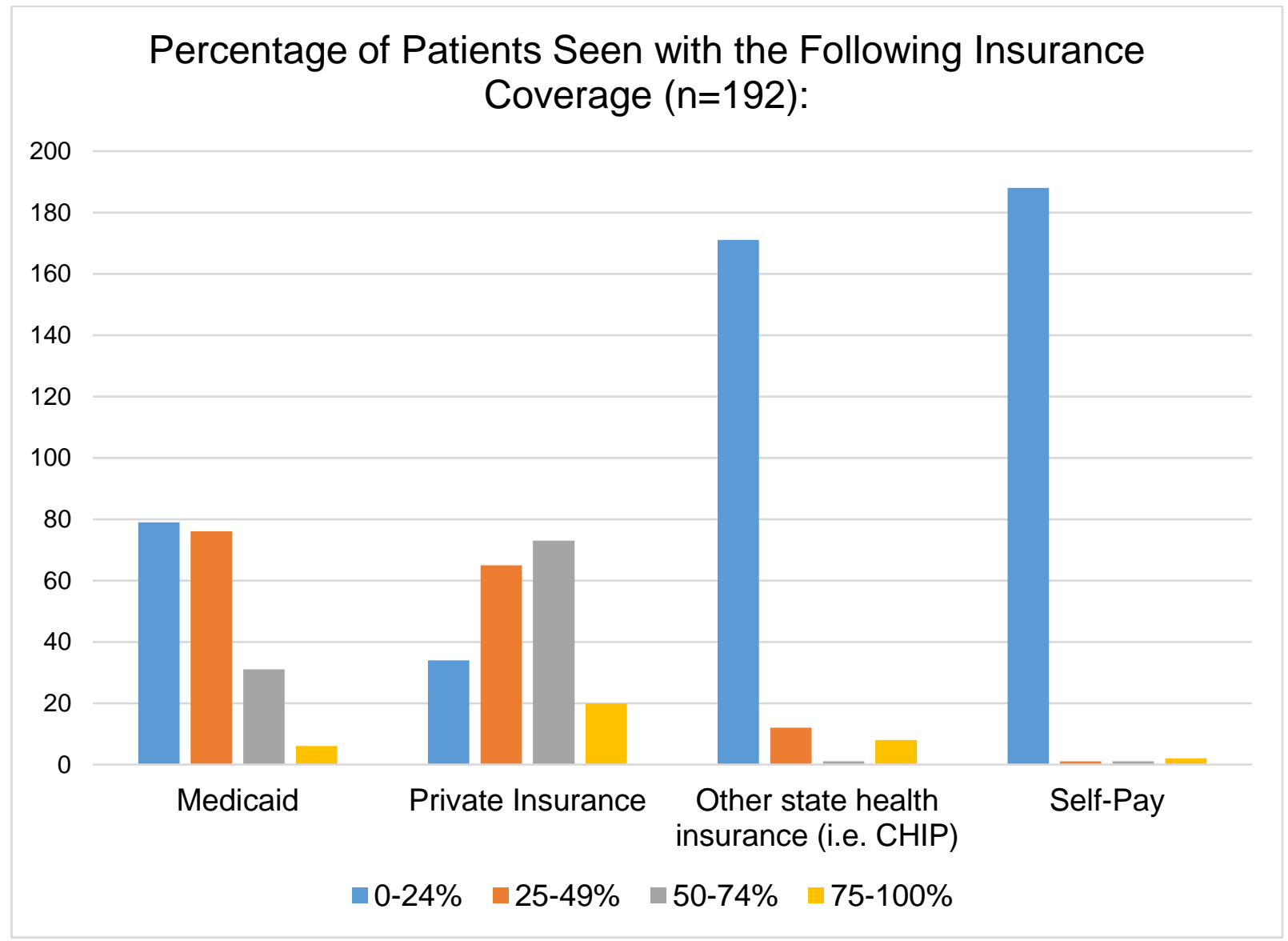

\section{Knowledge and Beliefs}

Participants were asked to describe their current level of knowledge regarding prenatal CMA, with most reporting they felt they were either an expert and could teach others, or that they were comfortable ordering the test without further education ( $n=163,85 \%)$. The majority reported to be current with clinical guidelines for the use of prenatal CMA $(n=166,86 \%)$. A little over half agreed that CMA should be offered to all patients regardless of indication $(n=99,52 \%)$ and a larger portion agreed that the benefits of CMA in its current form outweighed the harms $(n=123$, 64\%) (Table 3). 
Table 2. Knowledge and Beliefs

\begin{tabular}{|c|c|c|}
\hline Knowledge and Beliefs & $\mathrm{N}=192$ & Percentage \\
\hline \multicolumn{3}{|c|}{ Level of knowledge regarding prenatal microarray } \\
\hline Expert & 53 & $28 \%$ \\
\hline Comfortable no need for further education & 110 & $57 \%$ \\
\hline Comfortable, would like more education & 27 & $14 \%$ \\
\hline Basic knowledge & 1 & $0.5 \%$ \\
\hline No knowledge & 1 & $0.5 \%$ \\
\hline \multicolumn{3}{|c|}{ Familiar with current clinical guidelines for prenatal microarray } \\
\hline Yes & 166 & $86 \%$ \\
\hline No & 3 & $2 \%$ \\
\hline Unsure & 23 & $12 \%$ \\
\hline \multicolumn{3}{|c|}{$\begin{array}{l}\text { I believe prenatal microarray should be offered to all women regardless of } \\
\text { indication }\end{array}$} \\
\hline Agree/Somewhat agree & 99 & $51 \%$ \\
\hline
\end{tabular}




\begin{tabular}{|c|c|c|}
\hline Neutral & 11 & $6 \%$ \\
\hline Disagree/Somewhat disagree & 82 & $43 \%$ \\
\hline $\begin{array}{r}\text { I believe that, in its current form, th } \\
\text { outweigh th }\end{array}$ & renat & rray \\
\hline Agree/Somewhat agree & 123 & $64 \%$ \\
\hline Neutral & 38 & $20 \%$ \\
\hline Disagree/Somewhat disagree & 31 & $16 \%$ \\
\hline
\end{tabular}

\section{Incorporation into Practice}

Genetic counselors were asked if they had incorporated prenatal CMA into their clinical practice by offering it as an option to patients, and the majority reported that they have ( $n=183,95.3 \%)$. Of the 9 participants who have not incorporated CMA into their clinical practice (Arm A), when asked if they anticipated that they would begin offering the test in the future, 5 were unsure when they would incorporate it into use, and 2 reported they would incorporate it within the next 6 months. Only 1 stated that they did not plan on offering prenatal CMA in their clinical practice.

For those who have incorporated it into their practice (Arm B), detailed questions were asked with the intent of evaluating their current utilization and practices. We put forward sampled indications, modeled on ACOG guidelines or based on indications genetic counselors might encounter in a clinical setting, and 
asked participants how frequently they offer prenatal CMA given that specific indication by using a Likert scale. Results are summarized in Figure 2.

Figure 2.

\section{Frequency Prenatal CMA is Offered Given the Following Indication $(n=183)$ :}

All patients with a structural fetal anomaly

Patients with a positive NIPT for microdeletion or microduplication

Patients with a personal or family history of microdeletion or microduplication

Patients presenting with fetal demise or stillbirth

Patients with a desire to know "all information possible"

All patients undergoing invasive testing, regardless of indication

All patients with a non-structural fetal anomaly

Patients with a positive screening for fetal aneuploidy

Patient of advanced maternal age (AMA)

All patient undergoing genetic counseling

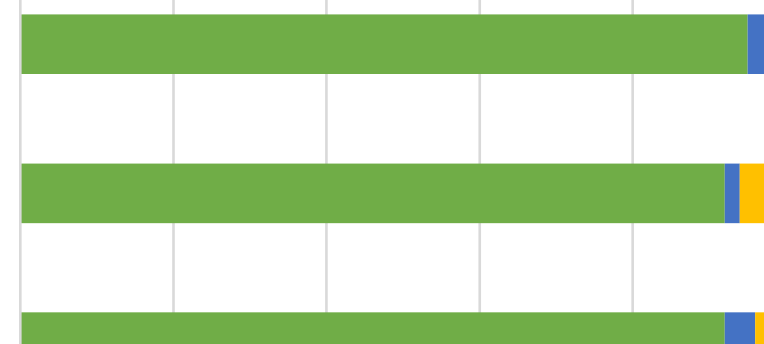

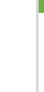

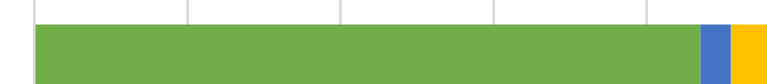


The greatest number of participants, $95 \%$, reported that they "mostly" or "always" offer CMA to patients with a structural fetal anomaly and $0 \%$ reported to "never" or "rarely" offering CMA for this indication. Eighty seven percent of the participants reported to "mostly" or "always" offer CMA to patients presenting with a fetal demise or stillbirth, and $71 \%$ reported to "mostly" or "always" offer CMA to their patients undergoing invasive testing. The participants that were offering CMA to patients undergoing invasive testing were significantly more likely to report feeling comfortable in their knowledge of CMA and did not need further education $(p=.011)$.

Participants who said they "rarely" or "never" offer CMA for fetal demise or stillbirth (9\%) were more likely to report that lack of data regarding yield and utility was influential in not offering the test, and were more likely to disagree that CMA should be offered to all patients, although these responses did not show statistical significance $(p=.435, p=.257)$. Participants who reported to "rarely" or "never" offer CMA to patients undergoing invasive testing (20\%) were significantly more likely to report that the difficulty of interpreting results was influential in not offering this test ( $p=.009)$ and were significantly more likely to disagree that CMA should be offered to all patients $(p<.001)$.

In general, the majority of participants reported "mostly" and "always" offering prenatal CMA for most of the sample indications. The exceptions were that, approximately an equal number of participants reported "rarely" or "never" $(45 \%)$ and "mostly" and "always" (44\%) offering CMA in the case of advanced maternal age (AMA), and $66 \%$ reported "rarely" or "never" offering CMA to all patient undergoing prenatal genetic counseling. Those that "mostly" or "always" offer CMA for AMA 
were significantly more likely to report being current with guidelines $(p=.023)$ and report being comfortable with their knowledge of CMA $(p=.001)$.

Of the participants who are not offering CMA for all patients undergoing counseling, this group was significantly more likely to report that patient specific concerns influenced this decision $(p=.047)$ as well as difficulty in interpreting results $(p=.009)$. Of the participants who are not offering CMA for all patients undergoing counseling and for patients who are AMA, this group was significantly more likely to disagree that prenatal CMA should be offered to all patients regardless of indication $(p<.001$ and $p<.001$ respectively). Those who were "never" or "rarely" offering CMA for AMA were significantly more likely to report desiring more education regarding $\operatorname{CMA}(p=.001)$.

Additionally, of the participants who reported "never" or "rarely" offering CMA to patients with non-structural abnormalities, a family history of microdeletion and microduplication syndromes, positive screen for aneuploidy, and patients who want all information possible, were more likely to say that lack of data plays a moderate/high degree of influence when not offering CMA ( $p=.001 ; p=.035 ; p=.004$, $p=.001$, respectively).

Frequency of use of CMA was compared to other demographic information provided by the participants, but no other statistically significant trends were encountered. 


\section{$\underline{\text { Barriers }}$}

Of the 9 genetic counselors who have not incorporated prenatal CMA into their practice, $89 \%(n=8)$ reported that financial concerns, as well as the possibility of receiving uncertain or ambiguous results $(89 \%, n=8)$, played a moderate to high degree of influence, followed by difficulty of interpreting results $(78 \%, n=7)$. In comparison, this group reported that patient specific concerns, such as anxiety or health literacy $(89 \%, n=8)$, and time constraints $(78 \%, n=7)$ had little influence. Due to the small sample size, further statistical analysis could not be performed.

Several reasons for not offering CMA were also reported by the 183 participants who offer prenatal CMA, including patient specific concerns (51\%), financial concerns (37\%), difficulty of interpreting results/lack of data (39\%), and time constraints (22\%). For participants who cited financial concerns as the reason for not offering CMA to patients, there were no statistically significant differences between the types of insurance their patients reportedly had ( $p=.198, p=.670, p=.868)$.

Barriers were compared to other demographic information provided by the participants, but no other statistically significant differences were encountered. Results are summarized in Figure 3. 
Figure 3.

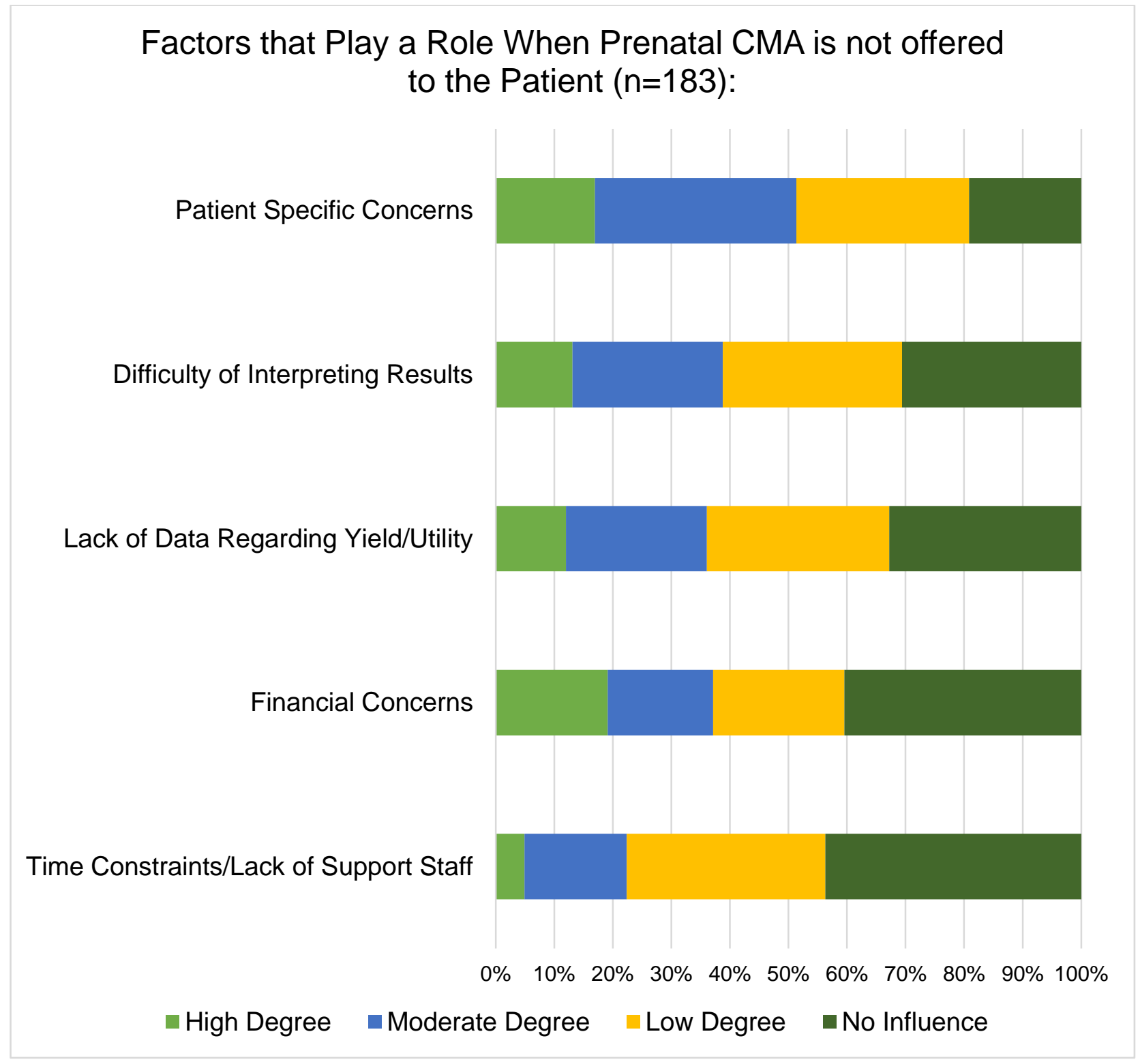

\section{Pre-Test and Test Ordering Practices}

Participants who have incorporated CMA into clinical practice were asked how frequently they discussed certain points during pre-test counseling (Figure 4). The points that were "mostly" or "always" discussed by the majority of participants include: CMA can yield a pathogenic or abnormal result (99\%), the severity of the 
phenotype may not be predictable (96\%), the results may be a VUS $(96 \%)$, results may have implications for the parents (74\%), and results can show incidental findings, such as non-paternity (68\%). However, approximately half of participants reported that they "rarely" or "never" discuss that results may indicated an adult onset disorder (48\%). Those that do not discuss adult onset disorders tended to have less than 10 years of experience, but this was not statistically significant ( $p=.072)$. This was also compared to other demographic information provided by the participants, but no other statistically significant trends were encountered.

On average, $55 \%$ of participants who have incorporated CMA into their practice reported ordering more than 10 prenatal CMAs per year and expanded arrays were ordered more often than targeted arrays (64\% vs. $33 \%$ ). Most participants $(57 \%)$ reported ordering SNP arrays more frequently than oligonucleotide arrays only (4\%) or combination arrays (oligonucleotide with SNP, $30 \%$ ). Those participants who ordered SNP arrays most often were less likely to work for an entity that performs CMA ( $p=.001)$. GCs that work with 5 or less GCs at their institution were significantly more likely to order SNP arrays $(p=.001)$ while those GCs who have $11+$ GCs at their institution were significantly more likely to order combination arrays $(p=.001)$. Forty-five percent of participants reported "mostly" or "always" ordering CMA in conjunction with a full karyotype, $25 \%$ reported ordering CMA only with no accompanying karyotype, and 15\% reported to ordering CMA with a limited or 5 cell karyotype. 
Approximately half of the participants reported only obtaining a verbal consent when consenting patients for CMA (51\%) followed by $43 \%$ that obtained both verbal and written consent. Many participants felt that incorporating CMA into their discussion during the session did not alter the length of an average genetic counseling session, but that the length varied based on the case specifics or clinical indication (55\%). Fifteen percent reported that they, or their institution, participated in data sharing, such as ClinGen, while $46 \%$ did not, and 39\% were unsure. Those who reported data sharing were significantly more likely to work for an academic institution $(p=.046)$. Working at a fetal center did not make a GC more likely to participate in data sharing $(p=.019)$ and neither did working for an institution that performs CMA $(p=.001)$. 
Figure 4.

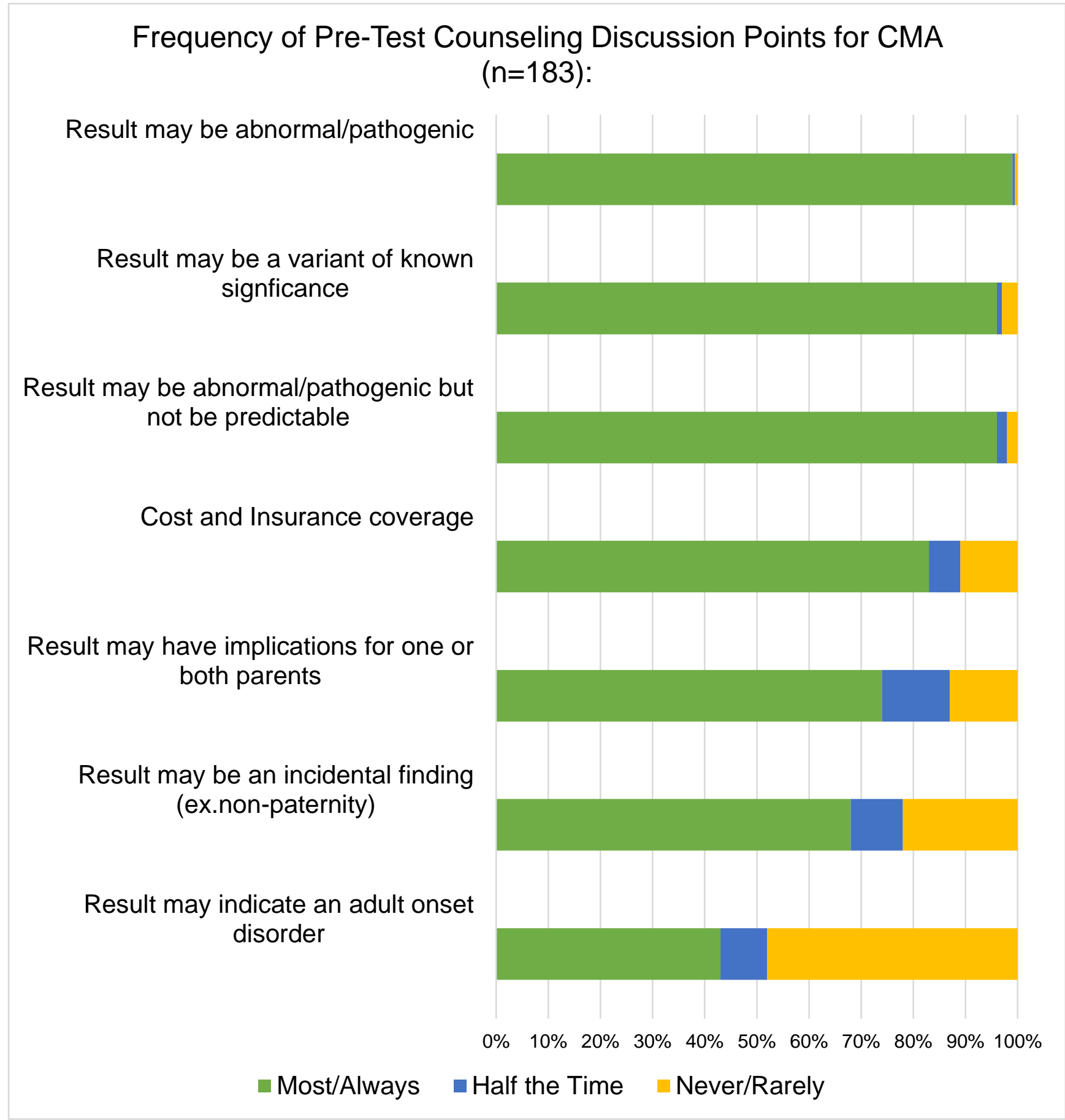




\section{$\underline{\text { Resources }}$}

Participants were asked what resources they use to stay current on information regarding prenatal CMA. The majority reported to stay current using the guidelines or practice bulletins from professional organizations $(n=176)$ followed by information gathered at national or scientific meetings $(n=160)$. The fewest number of participants reported using marketing material from commercial laboratories to stay current $(n=52)$. In the free response section, several participants stated that they utilize the expert knowledge and recommendations of laboratory genetic counselors, and that discussions with their colleagues were an important resource.

Figure 5.

\section{Resources Used to Stay Current on Information about Prenatal Microarray}

Guidelines or Practice Bulletins from professional organizations

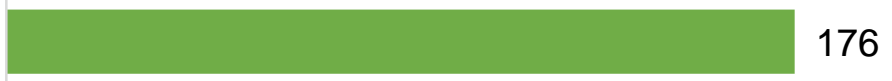

National or scientific meetings

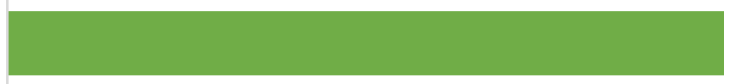

Review articles by experts on the topic

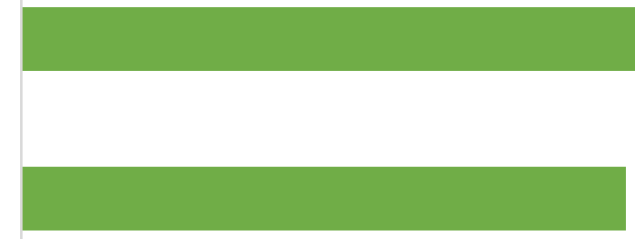

Marketing materials from commercial laboratories

None of the above 


\section{Discussion}

This study provides a cross-sectional view of current prenatal genetic counselors' practices and utilization of prenatal CMA, as well as barriers and challenges they encounter in North America. This is not the first study to evaluate genetic counselors' utilization, attitudes, and perceived barriers in relation to prenatal CMA, but it is the first study since ACOG published their guidelines and recommendations for its use in the prenatal setting.

This study demonstrates that nearly all prenatal genetic counselors surveyed have incorporated prenatal CMA into their clinical practice by offering it to their patients (95.3\%), with most ordering more than 10 arrays per year (55\%), and the majority feeling very comfortable in their current knowledge of prenatal CMA without desiring further education (83.3\%). This differs from the 2012 surveys that found only $84 \%$ of prenatal genetic counselors presented CMA to their patients, and that genetic counselors desired more education and resources about prenatal CMA testing ${ }^{16,17}$. This increase in utilization of prenatal CMA is likely due to a combination of factors, including the availability of guidelines set forth by professional organizations, number of discussions and presentations regarding CMA at national conferences such as the NSGC's Annual Education Conference, as well as the publication of peer-reviewed studies which further demonstrated the utility of CMA in the prenatal setting 2, 3, 8, 18-21.

This study also shows that the vast majority of genetic counselors surveyed (95\%) are offering prenatal CMA to patient's whose fetus has been identified with a 
structural anomaly, $87 \%$ are offering CMA in the presence of stillbirth or fetal demise, and $71 \%$ are offering CMA to all patients undergoing invasive testing demonstrating that overall prenatal genetic counselors are practicing in concordance with ACOG guidelines regarding utilization of CMA ${ }^{7}$.

Genetic counselors, however, were much less likely to offer CMA to all patients undergoing prenatal genetic counseling and those who are seen for routine indications, such as AMA. ACOG guidelines do not explicitly "recommend" but state that CMA "should be considered" for all women undergoing invasive testing, leaving it up to the provider to decide who to offer it to ${ }^{7}$. Most of the counselors who were offering CMA to patients cited patient specific concerns, such as anxiety and health literacy, as well as difficulty interpreting results as barriers to why they are not offering CMA in these situations. Although patient specific concerns was a newly reported barrier to offering prenatal CMA, the barrier of difficulty of interpreting results has been repeatedly reported in previously published studies ${ }^{16}$. Given the likelihood of finding a clinically significant CNV in pregnancies with common indications, like positive serum screening or AMA (1.3-1.7\%), is similar to the likelihood of finding a VUS on CMA (1.5-1.6\%), and evidence that VUS results significantly increase parental and family anxiety and distress ${ }^{3,15,22}$, this is not an unreasonable concern. More studies are needed; however, to explore how genetic counselors evaluate factors such as patient anxiety during a genetic counseling session when they are deciding whether to offer CMA.

Recommendations on the type of pre- and posttest counseling patients should receive prior to ordering a CMA have previously been recommended ${ }^{6}$ and 
reiterated by $\mathrm{ACOG}^{7}$. In our study, genetic counselors reported frequently reviewing the recommended pre-test counseling discussion points with patients (Figure 4) such as the types of results that CMA may yield. They also reported discussing financial concerns, such as insurance coverage and cost of testing, before testing is ordered. However, only about half of the genetic counselors reported discussing those results may indicate an adult onset disorder, despite ACOG guidelines. It is unclear from our study why this is so, but it may be due to the fact that at least $33 \%$ of counselors reported primarily ordering targeted arrays, which may decrease the chance of receiving these types of results. Further research into why certain results are not discussed as regularly with patients as other types of results, and the genetic counselors reasons for not doing so, would provide better insight into whether this decision is based mainly on the type of array ordered, the time constraints of the session, if it is a personal preference of the genetic counselor, or if there is a combination of factors effecting this decision.

Unlike preivously published concerns ${ }^{16}$, financial issues did not play as large of a role when counselors did not offer CMA as it did in the past. Increasing coverage of CMA testing by commercial insurance providers and the continually decreasing cost of CMA testing may be contributing factors. Insurance companies often conform to the recommendations of professional organizations, such as ACOG, and begin to cover new services when such recommendations are established ${ }^{6}$. When published medical policies from a few major insurance carriers were reviewed at the time this study was performed, many policies largely mirrored 
the language of the ACOG guidelines giving further evidence that insurance companies often utilize national guidelines when deciding patient coverage.

Overall, our study demonstrates that prenatal genetic counselors, despite practicing in many different settings and with varying years of experience, are utilizing CMA within the context of clinical guidelines. Genetic counselors reportedly follow pre-test counselling guidelines, believe that CMA is a useful test, and feel comfortable with their knowledge of CMA. Despite this, over half still believe that CMA should not be offered to all patients, regardless of indication, confirming the fact that more studies are still needed on the utility of CMA for all pregnant women.

We did not observe a need for further education on CMA technology, as the majority of counselors felt comfortable in their knowledge. However, the consistent barrier to ordering CMA appeared to be patient specific concerns, such as anxiety and health literacy. Therefore, further studies and education on CMA should continue to focus on providing more information on those factors which influence patient anxiety, such as receiving a VUS, and encourage more data sharing to further minimize the risk of uncertain results. Current guidelines and previous studies have alleviated earlier genetic counselors' concerns on the utility and yield of prenatal CMA for certain clinical indications, and have decreased certain barriers to ordering CMA such as ethical concerns, but there is still a lack of data and guidelines for how prenatal microarray should be utilized for other indications commonly seen by prenatal genetic counselors.

At this time there are no studies that focus on the patient specific concerns experienced by patients undergoing a discussion of prenatal microarray testing. A 
study looking at these patients concerns with an emphasis at teasing out what exactly are the specific underlying causes of those concerns could provide more information on how medical professions, specifically genetic counselors, could better address these concerns during their conversations with patients. Professional societies, particularly NSGC, may consider publishing guidelines that focus, not necessarily on when it should be clinically indication, but more so on evaluating and addressing patient specific concerns related to prenatal CMA. Established guidelines from NSGC would allow GCs access to guidelines specialized to their sphere of practice and further address some of the concerns noted in this study.

\section{Study Limitations}

This survey was distributed via email to the entire NSGC membership listserv and may represent a skewed population. Genetic counselors who either are not members of NSGC, or those who declined to receive student surveys, had their practices, experiences, and voices excluded. With any study, there is the inherit selection bias that those who take part may have an affinity for this subject matter or have very strong opinions regarding CMA, which may make them more likely to respond to the survey than those who find this subject less interesting. A large portion of genetic counselors who responded to this survey (24\%) reported working at a center that offered fetal intervention, which is a higher number than expected based on the number of fetal centers nationally, and may see a disproportionally higher number of patients with ultrasound anomalies than those with standard indications. 
Although our survey was distributed early in the fall semester, before the usual onslaught of student surveys were released upon the NSGC membership, there is the risk that we limited our participation because of survey fatigue experienced by NSGC members. Our survey was also designed to have forced responses, in other words, the participant could not move forward in the survey before answering the current question. We had many partially completed surveys, which were not included in our study, which may have been caused by this mandatory response setting and fatigue from answering a longer survey.

It was also impossible to calculate a response rate for our study. Per the 2016 professional survey, $43 \%$ are prenatal counselors that practice in a clinical setting. Based on how this survey was distributed, however, it is not possible to calculate how many NSGC members meet our eligibility criteria or how many received and/or opened the survey. This is because the email was sent to the entire NSGC membership, but there is not accurate data kept on who within the membership identify specifically as a clinical prenatal counselor. Because of this we only have the email open rate, which is also skewed by the fact that genetic counselors of other specialties, students, and other NSGC members opened the email. Additionally, the study was not based on validated measures and may have caused misinterpretation by the participants when answering the questions. 


\section{Appendix}

The Integration of Prenatal Microarray: A Survey of Current Genetic Counseling Practices and Barriers

1. To assess prenatal genetic counselors' practices regarding the utilization of prenatal microarray

2. To assess prenatal genetic counselors' perceived barriers regarding prenatal microarray

Members: Nevena Krstic, Blair Stevens, Sarah Jane Noblin, Dr. Ramesha Papanna, Dr. David Rodriguez

Do you consent to moving forward with the survey?

a. Yes, I wish to participate

b. No, I do not wish to participate

1. Do you provide prenatal genetic counseling?

a. Yes

b. No

If No Selected, Then Skip to End of Survey

2. Do you discuss prenatal diagnostic testing options, such as chorionic villus sampling (CVS) and amniocentesis, with patients?

a. Yes

b. No

If No Selected, Then Skip to End of Survey

3. Currently, how much of your time is spent counseling patients in the clinical prenatal setting?

a. $0 \%$

b. $1-20 \%$

c. $21-40 \%$ 

d. $41-60 \%$
e. $61-80 \%$
f. $81-100 \%$

If $0 \%$ Selected, Then Skip to End of Survey

4. Approximately how many prenatal patients do you see per week, including both new and follow-up patients?
a. $<5$
b. $6-10$
c. $11-15$
d. $16-20$
e. $>20$

5. How many years of total genetic counseling experience do you have?
a. $<5$
b. $6-10$
c. $11-15$
d. $16-20$
e. $>20$

6. How many years have you worked in the clinical prenatal setting?
a. $<5$
b. $6-10$
c. $11-15$
d. $16-20$
e. $>20$

7. What region do you currently practice in?

a. Region 1: CT, MA, ME, NH, NY, RI, VT, CN, Maritime Provinces

b. Region 2: DC, DE, MD, NJ, NY, PA, VA, WV, PR, VI, Quebec

c. Region 3: AL, FL, GA, KY, LA, MS, NC, SC, TN

d. Region 4: AR, IA, IL, IN, KS, MI, MN, MO, ND, NE, OH, OK, SD, WI, Ontario

e. Region 5: AZ, CO, MT, NM, TX, UT, WY, Alberta, Manitoba, Saskatchewan

f. Region 6: AK, CA, HI, NV, ID, OR, WA, British Columbia

8. What type of setting do you currently work in?

a. University Medical Center/Academic Institution

b. Private Hospital/Medical Facility

c. Public Hospital/Medical Facility 
d. Government or Military Hospital/Medical Facility

e. Private Practice/Office

f. Commercial Diagnostic Laboratory

g. Other (Please Specify):

9. In your primary work setting, roughly what percentages of your patients are in the following groups? (Please approximate; groups may not sum up to 100\%)

\begin{tabular}{|l|l|l|l|l|l|c|}
\hline & $0 \%$ & $1-9 \%$ & $10-24 \%$ & $25-49 \%$ & $50-74 \%$ & $\begin{array}{c}75- \\
100 \%\end{array}$ \\
\hline Private Insurance & & & & & & \\
\hline Medicaid & & & & & & \\
\hline $\begin{array}{l}\text { Other State Health } \\
\text { Insurance (ie. CHIP) }\end{array}$ & & & & & & \\
\hline Self Pay & & & & & & \\
\hline Other (please specify): & & & & & & \\
\hline
\end{tabular}

10. How many prenatal genetic counselors, other than yourself, currently work in your institution?
a. None, I am the only prenatal genetic counselor in my institution
b. $1-5$
c. $6-10$
d. $11-15$
e. $>15$

11. Do you currently work in a center that provides fetal interventions such as inutero spina bifida repair, twin-to twin transfusion laser surgery, etc.?
a. Yes
b. No
c. Unsure

12. Are you directly involved in counseling patients who are evaluated for and/or are candidates for fetal intervention?
a. Yes, I am directly involved
b. No, I am not directly involved
c. No, I am not directly involved but I refer patients who are evaluated for fetal intervention


13. What statement best describes your current level of knowledge regarding prenatal microarray?
a. I am an expert and can teach others about it
b. I am comfortable ordering the test without further education
c. I am comfortable ordering the test, but desire more education
d. I know the basics of the test but am not comfortable ordering it
e. I do not know anything about the test

14. Are you familiar with current clinical guidelines for use of prenatal microarray?
a. Yes
b. No
c. Unsure

15. Do you work for a hospital, laboratory, or commercial entity that also performs prenatal microarray?
a. Yes
b. No
c. Unsure

16. Please indicate to what extent you agree or disagree with the following statements:

\begin{tabular}{|l|c|c|c|c|c|}
\hline & Disagree & $\begin{array}{l}\text { Somewhat } \\
\text { Disagree }\end{array}$ & $\begin{array}{l}\text { Neither } \\
\text { Agree nor } \\
\text { Disagree }\end{array}$ & $\begin{array}{l}\text { Somewhat } \\
\text { Agree }\end{array}$ & Agree \\
\hline $\begin{array}{l}\text { I believe } \\
\text { prenatal } \\
\text { microarray } \\
\text { should be } \\
\text { offered to all } \\
\text { women, } \\
\text { regardless of } \\
\text { indication or } \\
\text { pursuit of } \\
\text { invasive testing }\end{array}$ & 0 & 0 & 0 & 0 & 0 \\
\hline $\begin{array}{l}\text { I believe that in } \\
\text { its current form, } \\
\text { the benefits of }\end{array}$ & 0 & 0 & 0 & 0 & \\
\hline
\end{tabular}




\begin{tabular}{|l|l|l|l|l|l|}
\hline $\begin{array}{l}\text { prenatal } \\
\text { microarray } \\
\text { outweigh the } \\
\text { harms }\end{array}$ & & & & & \\
\hline
\end{tabular}

17. Have you incorporated prenatal microarray into your clinical practice by offering it as an option?
a. Yes
b. No

If yes, skip to question 20

If no continue to next question

18. When do you anticipate that you or your institution will begin offering prenatal microarray in your clinical practice?
a. I do not plan to offer prenatal microarray in my clinical practice
b. Within the next 6 months
c. Within the next year
d. More than 1 year from now
e. Unsure

19. To what degree do the following factors play a role in why prenatal microarray has $\underline{\text { not }}$ been offered in your clinical practice?

\begin{tabular}{|l|c|c|c|c|}
\hline & $\begin{array}{l}\text { No } \\
\text { Influence }\end{array}$ & Low Degree & $\begin{array}{l}\text { Moderate } \\
\text { Degree }\end{array}$ & $\begin{array}{l}\text { High } \\
\text { Degree }\end{array}$ \\
\hline $\begin{array}{l}\text { Financial Concerns } \\
\text { (Cost, insurance } \\
\text { coverage, etc.) }\end{array}$ & 0 & $\circ$ & $\circ$ & $\circ$ \\
\hline $\begin{array}{l}\text { Possibility of } \\
\text { uncertain/ambiguous } \\
\text { results }\end{array}$ & 0 & 0 & 0 & 0 \\
\hline $\begin{array}{l}\text { Difficulty of interpreting } \\
\text { results (ie.VUS, } \\
\text { incidental findings) }\end{array}$ & $\circ$ & 0 & 0 & $\circ$ \\
\hline
\end{tabular}




\begin{tabular}{|l|c|c|c|c|}
\hline $\begin{array}{l}\text { Lack of knowledge or } \\
\text { data regarding } \\
\text { yield/utility }\end{array}$ & 0 & $\circ$ & 0 & 0 \\
\hline $\begin{array}{l}\text { Patient specific } \\
\text { concerns (health } \\
\text { literacy, anxiety, etc.) }\end{array}$ & 0 & 0 & 0 & 0 \\
\hline $\begin{array}{l}\text { Time constraints/lack of } \\
\text { support staff }\end{array}$ & 0 & 0 & 0 & 0 \\
\hline Other (please specify): & 0 & 0 & 0 & 0 \\
\hline
\end{tabular}

\section{End of Survey}

20. Please select the frequency with which you offer prenatal microarray given the following indication:

\begin{tabular}{|c|c|c|c|c|c|}
\hline & Never & Rarely & $\begin{array}{l}\text { About half } \\
\text { the time }\end{array}$ & $\begin{array}{l}\text { Most of } \\
\text { the time }\end{array}$ & Always \\
\hline $\begin{array}{l}\text { All patients undergoing } \\
\text { prenatal genetic } \\
\text { counseling }\end{array}$ & 0 & 0 & o & 0 & 0 \\
\hline $\begin{array}{l}\text { Patients undergoing } \\
\text { invasive testing, } \\
\text { regardless of indication }\end{array}$ & o & o & o & O & 0 \\
\hline $\begin{array}{l}\text { Patients with structural } \\
\text { fetal anomalies } \\
\text { (ie. cardiac; renal) }\end{array}$ & O & o & o & 0 & o \\
\hline $\begin{array}{l}\text { Patients with non- } \\
\text { structural fetal } \\
\text { anomalies } \\
\text { (ie. soft signs; IUGR; } \\
\text { polyhydramnios) }\end{array}$ & 0 & 0 & 0 & 0 & 0 \\
\hline $\begin{array}{l}\text { Patients of advanced } \\
\text { maternal age (AMA) }\end{array}$ & 0 & o & o & 0 & o \\
\hline $\begin{array}{l}\text { Patients with a positive } \\
\text { screening for fetal } \\
\text { aneuploidy }\end{array}$ & 0 & 0 & 0 & 0 & o \\
\hline
\end{tabular}




\begin{tabular}{|l|c|c|c|c|c|}
\hline $\begin{array}{l}\text { (ie. NIPT or serum } \\
\text { screening) }\end{array}$ & & & & \\
\hline $\begin{array}{l}\text { Patients with a positive } \\
\text { NIPT for } \\
\text { microdeletion/duplication }\end{array}$ & 0 & $\circ$ & 0 & 0 & 0 \\
\hline $\begin{array}{l}\text { Patients with a personal } \\
\text { or family history of } \\
\text { microdeletion/duplication }\end{array}$ & 0 & 0 & 0 & 0 & 0 \\
\hline $\begin{array}{l}\text { Patients presenting with } \\
\text { fetal demise/stillbirth }\end{array}$ & 0 & $\circ$ & 0 & 0 & 0 \\
\hline $\begin{array}{l}\text { Patients with a desire to } \\
\text { know "all information } \\
\text { possible" }\end{array}$ & 0 & 0 & 0 & 0 & 0 \\
\hline \begin{tabular}{l} 
Other (please specify): \\
\hline
\end{tabular} & 0 & 0 & 0 & 0 & 0 \\
\hline
\end{tabular}

21. To what degree do the following factors play a role when prenatal microarray is not offered to the patient?

\begin{tabular}{|l|c|c|c|c|}
\hline & No Influence & Low Degree & $\begin{array}{l}\text { Moderate } \\
\text { Degree }\end{array}$ & $\begin{array}{l}\text { High } \\
\text { Degree }\end{array}$ \\
\hline $\begin{array}{l}\text { Financial Concerns } \\
\text { (Cost, insurance } \\
\text { coverage, etc.) }\end{array}$ & 0 & 0 & 0 & 0 \\
\hline $\begin{array}{l}\text { Difficulty of interpreting } \\
\text { results (ie. VUS, } \\
\text { incidental findings) }\end{array}$ & 0 & 0 & 0 & 0 \\
\hline $\begin{array}{l}\text { Lack of data regarding } \\
\text { yield/utility }\end{array}$ & 0 & 0 & 0 & 0 \\
\hline $\begin{array}{l}\text { Patient specific } \\
\text { concerns (health } \\
\text { literacy, anxiety, etc.) }\end{array}$ & 0 & 0 & 0 & 0 \\
\hline $\begin{array}{l}\text { Time constraints/lack of } \\
\text { support staff }\end{array}$ & 0 & 0 & 0 & 0 \\
\hline \begin{tabular}{l} 
Other (please specify): \\
\hline
\end{tabular} & 0 & 0 & 0 & 0 \\
\hline
\end{tabular}


22. Approximately how many times have you ordered prenatal microarray in the last year?
a. 0
b. $1-5$
c. $6-10$
d. $>10$

23. Please select the frequency with which you order the following:

\begin{tabular}{|l|c|c|c|c|c|}
\hline & Never & Rarely & $\begin{array}{c}\text { About half } \\
\text { the time }\end{array}$ & $\begin{array}{c}\text { Most of } \\
\text { the time }\end{array}$ & Always \\
\hline Targeted array & $\circ$ & $\circ$ & $\circ$ & $\circ$ & $\circ$ \\
\hline Expanded array & $\circ$ & $\circ$ & $\circ$ & $\circ$ & $\circ$ \\
\hline
\end{tabular}

24. Please select the frequency with which you order the following:

\begin{tabular}{|l|c|c|c|c|c|}
\hline & Never & Rarely & $\begin{array}{c}\text { About half } \\
\text { the time }\end{array}$ & $\begin{array}{c}\text { Most of } \\
\text { the time }\end{array}$ & Always \\
\hline Array only & $\circ$ & $\circ$ & $\circ$ & $\circ$ & $\circ$ \\
\hline Array with full karyotype & $\circ$ & $\circ$ & $\circ$ & $\circ$ & 0 \\
\hline $\begin{array}{l}\text { Array with limited/5 cell } \\
\text { count karyotype }\end{array}$ & $\circ$ & $\circ$ & $\circ$ & $\circ$ & 0 \\
\hline
\end{tabular}

25. What type of array do you most frequently order?
a. Oligonucleotide array
b. SNP array
c. Combination (oligo and SNP) array
d. Unsure 
26. At present, how is informed consent for prenatal microarray obtained in your clinic?
a. Verbal consent
b. Written consent
c. Verbal and written consent
d. Other (please specify):

27. Has the amount of time it takes to complete a genetic counseling session changed with implementation of prenatal microarray into your practice?
a. Yes, it has become longer
b. Yes, it has become shorter
c. No change
d. Varies based on case/clinical situation
e. Unsure

28. How frequently do you discuss the following during pre-test counseling for prenatal microarray?

\begin{tabular}{|l|c|c|c|c|c|}
\hline & Never & Rarely & $\begin{array}{c}\text { About half } \\
\text { the time }\end{array}$ & $\begin{array}{c}\text { Most of } \\
\text { the time }\end{array}$ & Always \\
\hline $\begin{array}{l}\text { Result may be } \\
\text { abnormal/pathogenic }\end{array}$ & 0 & 0 & 0 & 0 & 0 \\
\hline $\begin{array}{l}\text { Result may be } \\
\text { abnormal/pathogenic } \\
\text { but the nature or } \\
\text { severity of the } \\
\text { defects/disease may } \\
\text { not be predictable }\end{array}$ & 0 & 0 & 0 & 0 & 0 \\
\hline $\begin{array}{l}\text { Result may indicate an } \\
\text { adult onset disorder }\end{array}$ & 0 & 0 & 0 & 0 & 0 \\
\hline $\begin{array}{l}\text { Result may have } \\
\text { implications for one or } \\
\text { both of the parents }\end{array}$ & 0 & 0 & 0 & 0 & 0 \\
\hline
\end{tabular}




\begin{tabular}{|l|c|c|c|c|c|}
\hline $\begin{array}{l}\text { Result may be a variant } \\
\text { of unknown significance } \\
\text { (VUS/VOUS) }\end{array}$ & 0 & 0 & 0 & 0 & 0 \\
\hline $\begin{array}{l}\text { Result may be an } \\
\text { incidental finding (non- } \\
\text { paternity, } \\
\text { consanguinity, incest, } \\
\text { etc.) }\end{array}$ & 0 & 0 & 0 & 0 & 0 \\
\hline $\begin{array}{l}\text { Cost and insurance } \\
\text { coverage }\end{array}$ & 0 & 0 & 0 & 0 & 0 \\
\hline
\end{tabular}

29. Do you or your institution participate in data sharing (ie. ClinGen)?
a. Yes
b. No
c. Unsure

30. What resources do you use to stay current on information about prenatal microarray? Select all that apply

_ Guidelines or Practice Bulletins from Professional Organizations

_Peer-reviewed journals

_ Review articles by experts on the topic

_National or scientific meetings

_.Marketing material from commercial laboratories

_ Other (please specify):

None of the above

Thank you for taking part in this survey. If you wish to take part in the drawing for 2 $\$ 50$ Amazon gift cards please email Leslie.Durham@uth.tmc.edu with the subject line microarray drawing. Your survey responses will not be linked to your email. 


\section{Bibliography:}

1. Shaffer, L. G.; Dabell, M. P.; Fisher, A. J.; Coppinger, J.; Bandholz, A. M.; Ellison, J. W.; Ravnan, J. B.; Torchia, B. S.; Ballif, B. C.; Rosenfeld, J. A., Experience with microarray-based comparative genomic hybridization for prenatal diagnosis in over 5000 pregnancies. Prenat Diagn 2012, 32 (10), 976-85.

2. Miller, D. T.; Adam, M. P.; Aradhya, S.; Biesecker, L. G.; Brothman, A. R.; Carter, N. P.; Church, D. M.; Crolla, J. A.; Eichler, E. E.; Epstein, C. J.; Faucett, W. A.; Feuk, L.; Friedman, J. M.; Hamosh, A.; Jackson, L.; Kaminsky, E. B.; Kok, K.; Krantz, I. D.; Kuhn, R. M.; Lee, C.; Ostell, J. M.; Rosenberg, C.; Scherer, S. W.; Spinner, N. B.; Stavropoulos, D. J.; Tepperberg, J. H.; Thorland, E. C.; Vermeesch, J. R.; Waggoner, D. J.; Watson, M. S.; Martin, C. L.; Ledbetter, D. H., Consensus statement: chromosomal microarray is a first-tier clinical diagnostic test for individuals with developmental disabilities or congenital anomalies. Am J Hum Genet 2010, $86(5), 749-64$.

3. Wapner, R. J.; Martin, C. L.; Levy, B.; Ballif, B. C.; Eng, C. M.; Zachary, J. M.; Savage, M.; Platt, L. D.; Saltzman, D.; Grobman, W. A.; Klugman, S.; Scholl, T.; Simpson, J. L.; McCall, K.; Aggarwal, V. S.; Bunke, B.; Nahum, O.; Patel, A.; Lamb, A. N.; Thom, E. A.; Beaudet, A. L.; Ledbetter, D. H.; Shaffer, L. G.; Jackson, L., Chromosomal microarray versus karyotyping for prenatal diagnosis. $N$ Engl $J$ Med 2012, $367(23), 2175-84$.

4. Genetics, A. C. o. O. a. G. C. o., Committee Opinion No. 581: the use of chromosomal microarray analysis in prenatal diagnosis. Obstet Gynecol 2013, 122 (6), 1374-7. 
5. Practice Bulletin No. 162: Prenatal Diagnostic Testing for Genetic Disorders. Obstet Gynecol 2016.

6. Dugoff, L.; Norton, M. E.; Kuller, J. A.; pubs@smfm.org, S. f. M.-F. M. S. E.

a., The use of chromosomal microarray for prenatal diagnosis. Am J Obstet Gynecol 2016, $215(4)$, B2-9.

7. Committee Opinion No.682: Microarrays and Next-Generation Sequencing Technology: The Use of Advanced Genetic Diagnostic Tools in Obstetrics and Gynecology. Obstet Gynecol 2016, 128 (6), e262-e268.

8. Brady, P. D.; Delle Chiaie, B.; Christenhusz, G.; Dierickx, K.; Van Den Bogaert, K.; Menten, B.; Janssens, S.; Defoort, P.; Roets, E.; Sleurs, E.; Keymolen, K.; De Catte, L.; Deprest, J.; de Ravel, T.; Van Esch, H.; Fryns, J. P.; Devriendt, K.; Vermeesch, J. R., A prospective study of the clinical utility of prenatal chromosomal microarray analysis in fetuses with ultrasound abnormalities and an exploration of a framework for reporting unclassified variants and risk factors. Genet Med 2014, 16 (6), 469-76.

9. $\quad$ Bragin, E.; Chatzimichali, E. A.; Wright, C. F.; Hurles, M. E.; Firth, H. V.; Bevan, A. P.; Swaminathan, G. J., DECIPHER: database for the interpretation of phenotype-linked plausibly pathogenic sequence and copy-number variation.

Nucleic Acids Res 2014, 42 (Database issue), D993-D1000.

10. Coordinators, N. R., Database resources of the National Center for Biotechnology Information. Nucleic Acids Res 2016, 44 (D1), D7-D19.

11. Richards, S.; Aziz, N.; Bale, S.; Bick, D.; Das, S.; Gastier-Foster, J.; Grody, W. W.; Hegde, M.; Lyon, E.; Spector, E.; Voelkerding, K.; Rehm, H. L.; Committee, 
A. L. Q. A., Standards and guidelines for the interpretation of sequence variants: a joint consensus recommendation of the American College of Medical Genetics and Genomics and the Association for Molecular Pathology. Genet Med 2015, 17 (5), 405-24.

12. Shield, A. B. C. a. B. Chromosomal Microarray Analysis (CMA) for Developmental Delay, Autism Spectrum Disorder, Intellectual Disability (Intellectual Developmental Disorder) and Congenital Anomalies.

13. Aetna Comparative Genomic Hybridization (CGH) Policy Number 0787. http://www.aetna.com/cpb/medical/data/700 799/0787.html.

14. Healthcare, U. Chromosome Microarray Testing Policy Number: 2017T0559H.

https://www.unitedhealthcareonline.com/ccmcontent/ProviderlI/UHC/enUS/Assets/ProviderStaticFiles/ProviderStaticFilesPdf/Tools\%20and\%20Resources/ Policies\%20and\%20Protocols/Medical\%20Policies/Medical\%20Policies/Chromosom e Microarray Testing.pdf.

15. Wapner, R. J.; Driscoll, D. A.; Simpson, J. L., Integration of microarray technology into prenatal diagnosis: counselling issues generated during the NICHD clinical trial. Prenat Diagn 2012, 32 (4), 396-400.

16. Mikhaelian, M.; Veach, P. M.; MacFarlane, I.; LeRoy, B. S.; Bower, M., Prenatal chromosomal microarray analysis: a survey of prenatal genetic counselors' experiences and attitudes. Prenat Diagn 2013, 33 (4), 371-7. 
17. Bernhardt, B. A.; Kellom, K.; Barbarese, A.; Faucett, W. A.; Wapner, R. J., An exploration of genetic counselors' needs and experiences with prenatal chromosomal microarray testing. J Genet Couns 2014, 23 (6), 938-47.

18. Ellison, J. W.; Ravnan, J. B.; Rosenfeld, J. A.; Morton, S. A.; Neill, N. J.; Williams, M. S.; Lewis, J.; Torchia, B. S.; Walker, C.; Traylor, R. N.; Moles, K.; Miller, E.; Lantz, J.; Valentin, C.; Minier, S. L.; Leiser, K.; Powell, B. R.; Wilks, T. M.; Shaffer, L. G., Clinical utility of chromosomal microarray analysis. Pediatrics 2012, 130 (5), e1085-95.

19. Hillman, S. C.; McMullan, D. J.; Hall, G.; Togneri, F. S.; James, N.; Maher, E. J.; Meller, C. H.; Williams, D.; Wapner, R. J.; Maher, E. R.; Kilby, M. D., Use of prenatal chromosomal microarray: prospective cohort study and systematic review and meta-analysis. Ultrasound Obstet Gynecol 2013, 41 (6), 610-20.

20. Reddy, U. M.; Page, G. P.; Saade, G. R., The role of DNA microarrays in the evaluation of fetal death. Prenat Diagn 2012, 32 (4), 371-5.

21. Rosenfeld, J. A.; Tucker, M. E.; Escobar, L. F.; Neill, N. J.; Torchia, B. S.; McDaniel, L. D.; Schultz, R. A.; Chong, K.; Chitayat, D., Diagnostic utility of microarray testing in pregnancy loss. Ultrasound Obstet Gynecol 2015, 46 (4), 47886.

22. Werner-Lin, A.; Barg, F. K.; Kellom, K. S.; Stumm, K. J.; Pilchman, L.;

Tomlinson, A. N.; Bernhardt, B. A., Couple's Narratives of Communion and Isolation Following Abnormal Prenatal Microarray Testing Results. Qual Health Res 2016, 26 (14), 1975-1987. 


\section{Vita:}

Leslie Durham was born in Wichita Falls, Texas on September 12, 1986, the daughter of Renee and Steven Durham. After graduating from Coppell High School, Coppell, Texas in 2005, she entered the University of North Texas in Denton, Texas. She received a Bachelor of Arts degree in Spanish in August of 2009 and a Bachelor of Science degree in Biology with a minor in Chemistry in May 2010. For two years after graduation she worked for the Spanish Ministry of Education as an English teacher, teaching ages 5-16, in Valdovino, Spain. In August of 2015 she entered The University of Texas MD Anderson Cancer Center UTHealth Graduate School of Biomedical Sciences to begin work on her Master of Science in Genetic Counseling.

\section{Permanent Address:}

Leslie Durham

11209 Park Central Place

Dallas, Texas 75230 